\title{
PERFORMING ANAPHORA IN MODERN GREEK: A NeO-GricEAN PRAGMATIC ANALYSIS
}

\author{
MICHAEL CHIOU \\ M.A., PhD in Linguistics, University of Reading, UK \\ mchiou1234@gmail.com
}

\begin{abstract}
The paper addresses the problem of interpreting anaphoric NPs in Modern Greek. It includes a proposal of a novel analysis based on the systematic interaction of the neoGricean pragmatic principles of communication, which provides a neat and elegant approach to NP-anaphora resolution.

The findings of this study provide evidence for an account of NP-anaphora in terms of the division of labour between syntax and pragmatics and more accurately in terms of the systematic interaction of the neo-Gricean pragmatic principles.
\end{abstract}

Keywords: anaphora, pragmatics, syntax, Grice

\section{Setting the scene}

The interpretation of anaphoric expressions is one of the core issues in linguistics. Understanding and explaining the phenomenon of anaphora, as it is termed, which refers to the relation between two noun phrases (henceforth NPs), wherein the interpretation of the one (the anaphoric expression) is fixed upon the interpretation of the other (the antecedent), constitutes one of the most intriguing and controversial topics in linguistic research.

Anaphora is a cross-linguistic phenomenon and it is realised differently across languages. To borrow two terms from biology, we can say that on the one hand, there is a certain genotype of anaphora, which is common to all natural languages and on the other hand, there are various phenotypes, i.e. observable variations in the realisation of the phenomenon.

In this paper I will mainly focus on NP-anaphora in Modern Greek and I will show that the established syntactic accounts of the phenomenon cannot adequately describe and explain the whole range of anaphoric patterns. I shall present evidence according to which NP-anaphora patterns in Modern Greek are inherently pragmatic in nature and anaphora resolution involves preferred interpretations following from conversational inferences. Given this, a way forward is to propose that NP-anaphora in Modern Greek can be explained more elegantly in terms of the division of labour between syntax and pragmatics and more precisely, in terms of the systematic interaction of pragmatic principles of communication such as the neo-Gricean pragmatic principles in the spirit of Levinson (1991, 2000) and Huang (1994, 2000). 
The remainder of the paper is organised as follows. Section 2 offers an overview of the basic distributional facts of NP-anaphora in Modern Greek. In section 3, we present an up-to-date review of the generative approaches to Modern Greek NP-anaphora. The proposed partial neo-Gricean pragmatic analysis is presented in section 4 .

\section{Some basic facts}

In this section, I shall present the basic distributional facts of Modern Greek NPanaphora, focusing mainly on the classification and the syntactic distribution of anaphors and pronominals (overt and zero).

\subsection{Typology}

For our purposes we are going to follow the typology of NPs as introduced in Chomsky (1982, 1986). According to this typology, anaphoric NPs are described and classified in terms of two polarized abstract features namely [+/-anaphor] and [+/-pronominal] thus giving us four different types of NPs.

In the case of Modern Greek, NPs can be classified as follows:

\begin{tabular}{|lll|}
\hline & \multicolumn{1}{c}{ overt } & \multicolumn{1}{c|}{ empty } \\
\hline$[+$ anaphor, -pronominal $]$ & o eaftos mu & NP-trace \\
\hline$[$-anaphor, +pronominal $]$ & aftos/i/o, ton,tin,to & Pro \\
\hline$[+$ anaphor, +pronominal $]$ & ------ & ?PRO \\
\hline$[$-anaphor, -pronominal] & r-expressions & wh-trace/variable \\
\hline
\end{tabular}

Table 1: Classification of NPs in Modern Greek

In this paper I will mainly focus on the reflexive $o$ eaftos $m u$ which fills the overt anaphor position, the personal pronouns (overt and empty) which are described as pronominals and finally, the r-expressions which fill the overt [-anaphor, -pronominal] position. Note however that there is an anaphoric expression missing from the table, namely $o$ idjos. This is an anaphor of a special type that does not fit neatly into this classification; we shall return to the case $o$ idjos of in our discussion. Finally, $\mathrm{PRO}^{1}$ will not be discussed since it is not within the scope of this paper.

\subsection{The reflexive $o$ eaftos $m u$}

One way of expressing reflexivity is by the reflexive pronoun o eaftos $m u$ (myself). It is formed by the definite article $o$ (the) in masculine gender, the noun eaftos (self) and the possessive pronoun $m u$ (my) in the appropriate person, number and gender in agreement

\footnotetext{
${ }^{1}$ For details on PRO see Iatridou (1993), Karanasios (1989), Philippaki-Warburton (1987),
} Philippaki-Warburton \& Catsimali (1999), Terzi (1991, 1993) and Varlokosta (1993, 1994). 
with its antecedent. The possessive pronoun appears only in genitive case. Moreover, the agreement in number between the noun and the possessive is not necessary, for instance, (ton eafto-sg tu-sg) and (ton eafto-sg tus-pl).

As Joseph \& Philippaki-Warburton (1987: 79) note, o eaftos mu can occur in various positions in the clause, "more specifically in whatever position a noun phrase bearing the same syntactic relation can occur". The reflexive pronoun o eaftos $m u$ can function as an object, subject, object of an adjective, passive agent and object of prepositions ${ }^{2}$ as it is illustrated in examples (1) - (5) respectively (for more examples see Joseph \& Philippaki-Warburton 1987, Holton et al 1997 and Chiou 2010).

1) O Janis arapai ton eafto tu the John loves the self-acc his 'John loves himself.'

2) $\mathrm{O}$ eaftos mu ftei ja ola the self-nom my is responsible for everything 'Myself is responsible for everything.'

3) Jati $\delta$ en ise kalos me ton eafto su? why not are-2sg good with the self-acc your 'Why are you not good with yourself?'

4) $\mathrm{O}$ Janis plironete apo ton eafto tu the John is hurt by the self-acc his 'John hurts himself.'

5) O Janis milai panda ja ton eafto tu the John speaks always for the self-acc his 'John speaks always for himself.'

\section{$2.3 \mathrm{O}$ iojos}

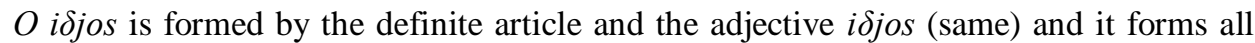
three genders in both numbers. It can be found mainly in two positions, namely, in a subject or in an object position (direct or indirect). Consider examples (6) and (7) respectively.

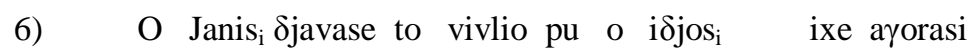
the John read the book that the same-nom had bought 'John read the book that he himself had bought.'

\footnotetext{
${ }^{2}$ Holton et al. (1997) as well as Joseph \& Philippaki-Warburton (1987: 80) note that the reflexive o eaftos mu does not occur with other locatival complex prepositions, for instance, *dhipla ston eafto ти (next to myself), *piso apo ton eafto mu (behind myself) etc. However, expressions such as enantia ston eafto ти (against myself), gyro/ekso apo ton eafto ти (round/outside myself) may occur.
} 


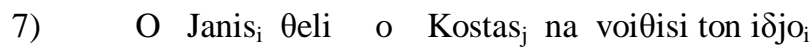
the John wants the Kostas to help the same-acc 'John wants Kostas to help him.'

When in object position, $o$ idjos cannot appear in relative clauses and cannot have a quantifier as its antecedent, see (8) and (9). By contrast, subject $o$ i $\delta j o s$ allows for the above distributions, see for instance example (6).

8) $\quad *$ O Janis ${ }_{\mathrm{i}}$ arapai tin kopela pu filise ton $\mathrm{i}_{\mathrm{j} \mathrm{jo}_{\mathrm{i}}}$ the John loves the girl who kissed the same-acc 'John loves the girl who kissed himself.'

9) *KaӨenas $\mathrm{K}_{\mathrm{i}}$ nomizi oti o Janis ayapai ton $\mathrm{i} \delta \mathrm{jo}_{\mathrm{i}}$ everyone thinks that the John loves the same-acc 'Everyone thinks that John loves him.'

\subsection{Personal pronouns}

Personal pronouns occur in both numbers (singular and plural), in all three persons, namely, eyo, esi, aftos/afti, emis, esis, afti/aftes (I, you, he/she, we, you, they) and form all cases. As Mackridge (1985: 145) notes, "personal pronouns are divided into emphatic and non-emphatic (clitic) pronouns" There is a difference between emphatic and nonemphatic pronouns both in their function and form. More precisely, "the emphatic forms are typically disyllabic or trisyllabic and are stressed on the second syllable whereas the clitics are unstressed monosyllables" (Mackridge 1985: 145). Clitic forms function as direct or indirect objects and they normally precede the verb forms, except for imperatives and the present participles where they follow the verb (Mackridge 1985).

What is more, given that Modern Greek is a typical pro-drop language, it normally drops the overt subject personal pronouns. As a result, the class of pronominals can also appear as an empty category. By way of illustration consider the example:

10) $\varnothing \quad$ ipe oti $\varnothing \quad \theta$ a $\delta$ javazi perisotero

(She/he) said that (she/he) will study more

'She/he said that she/he will study more.'

As Joseph \& Philippaki-Warburton (1987) state, full pronouns are optional in their occurrence. Their presence is usually associated with emphasis or contrast and they are considered more marked choice when use instead of a zero pronoun (Holton et al. 1997). The referential properties of zero pronouns are similar to the overt ones. In addition, null subject languages like Modern Greek also exhibit two other properties: a) they have free subject inversion, and b) they can extract the subject long-distance over a lexically filled complementizer (Huang 2000). 
11) Sto sxolio pire o Janis to the school went the John

'John went to school.'

12) Pjos nomizis oti irӨe simera spiti? who think-2sg that came today home

'Who do you think that came home today?'

In this paper, we are more interested in third person pronouns, either in their full form aftos, afti, afto (he, she, it), their non-emphatic or clitic form tu, tis, to or in the zero form.

\section{The syntax of NP-anaphora}

The most influential theory which has offered a systematic and principled approach to NP-anaphora in Modern Greek has been Chomsky's binding theory within the framework of the principles-and-parameters theory.

\subsection{Binding principles}

Following Chomsky (1982, 1986) the interpretation of lexical anaphors, pronominals (overt and zero) and r-expressions is regulated by the three binding principles or conditions in (13).

13) Chomsky's binding principles (Chomsky 1995: 96).

Principle A: An anaphor must be bound in a local domain.

Principle B: A pronominal must be free in a local domain.

Principle C: An r-expression must be free.

The definition of binding is given in (14) below:

14) $\quad \alpha$ binds $\beta$ iff:

i) $\alpha$ is in an A-position

ii) $\alpha$ c-commands $\beta$, and

iii) $\alpha$ and $\beta$ are coindexed

Note that given (14i), the binding conditions are relevant to NPs occupying $\theta$-marked positions which are in principle $\mathrm{A}$ (rgument)-positions. Consequently, A-binding is distinguished from A'-binding, with the latter being relevant to binding of variables which occupy A'-positions. Finally c-command is defined in (15). 
15) $\quad \alpha$ c-commands $\beta$ iff:

i) $\alpha$ does not dominate $\beta$,

ii) $\beta$ does not dominate $\alpha$,

iii) the first branching node dominating $\alpha$ also dominates $\beta$

C-command distinguishes syntactic binding from co-reference, which is a semantic notion.

Following the above rules and principles, the paradigmatic patterns for binding in Modern Greek can be described along the following lines: The reflexive o eaftos $m u^{3}$ appears to be a typical example of a [+anaphor] [-pronominal] NP and thus it should be bound by a local antecedent.

16) I Maria Oavmazi ton eafto tis $_{i}$ the Mary admires the self hers 'Mary admires herself.'

17) * Maria $a_{i}$ ipe oti o eaftos tis ine kalos sto piano the Mary said that the self her is good at the piano 'Mary said that herself is good at playing the piano.'

In (16) o eaftos $m u$ is co-indexed with a local antecedent, which is grammatically acceptable whereas in (17) we have an ungrammatical sentence since the reflexive appears to receive a non-local antecedent violating thus binding condition A. Therefore, the distribution of the Modern Greek reflexive o eaftos mu in examples (16) and (17) follows straightforwardly from binding principle A. Moreover, according to principle B, a pronominal is free in its local domain. This is borne out in Modern Greek for the personal pronouns either overt or zero as it is illustrated in the examples (18) and (19).

18)

O Janis $\mathrm{J}_{\mathrm{i}}$ ipe oti $\emptyset_{\mathrm{i}}$ tha Siavazi perisotero

the John said that (he) will study more

'John said that he will study more.'

19) *O Janis ton $_{\mathrm{i}}$ kseri poli kala

the John him knows very well

'John knows him very well.'

The ungrammaticality of (19) follows from the violation of binding principle B since the clinic pronoun ton is co-indexed locally. Finally, in an unmarked context examples like (20) are also ungrammatical since they violate binding principle $\mathrm{C}$.

20) $*$ O Janis $_{\mathrm{i}}$ Өavmazi ton Jani $\mathrm{i}_{\mathrm{i}}$ the John admires the John

'John admires John.'

\footnotetext{
${ }^{3}$ For the reflexive o eaftos mu see also Iatridou (1988); see also Anagnostopoulou \& Everaert (1999) for an analysis within the semantic/argument structure approach.
} 


\subsection{Problematic issues}

\subsubsection{Problems with principles $A$ and $B$}

Cross linguistic evidence has shown that the binding principles run into great difficulties in particular with languages that allow the long-distance binding of reflexives/anaphors (e.g. the majority of Asian languages, some Scandinavian, Germanic and Romance languages), but also with languages that lack reflexives altogether using thus pronominals for encoding co-reference locally (e.g. Astronesian and Papuan languages), (see Huang 2000 for more).

In Modern Greek too, there are certain cases which are problematic for the classical binding theory. To begin with, the reflexive o eaftos $m u$ is not an exception to longdistance binding effects. Consider the following example:

21) $\varnothing_{\mathrm{i}} \mathrm{mu}$ ipe na fero mia efimeriða ja ton $\mathrm{Jani}_{\mathrm{j}}$ ke (He) me said-3sg to bring one newspaper for the John and mia ja ton eafto tu $\mathrm{i}_{\mathrm{i}}$ one for the self his 'He told me to bring one newspaper for John and one for himself.'

In addition, there is the well know case 'picture' NPs.

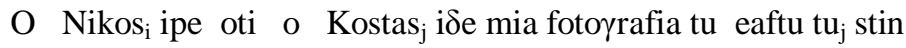

$$
\begin{aligned}
& \text { the Nick said that the Kostas saw a picture the self his in the } \\
& \text { efimerioa } \\
& \text { newspaper } \\
& \text { 'John said that Kostas saw a picture of himself/him in the newspaper.' }
\end{aligned}
$$

Examples like (21) and (22) challenge a purely local account of reflexive o eaftos mu. In example (21), even if there isn't a strict violation of binding condition A, since there is no c-command relationship, there is an issue for a purely local account of the reflexive as it should be accepted that there is another version of $o$ eaftos $m u$ which does not fall under binding condition A. Also in (22), the alleged complementarity in reference between reflexives and pronominals, arising from the mirror effect of binding conditions A and B, breaks down.

Coming to pronouns, despite the fact that both overt and zero pronouns are subject to binding condition $\mathrm{B}$, it has been shown that they are not in free variation. As example (23) illustrates, there are cases in which the use of an overt pronoun instead of a zero one can change reference, which is not predicted by binding condition $\mathrm{B}$.

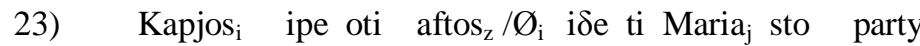
somebody said that he (he) saw the Mary at the party 'Somebody said that he saw Mary at the party.' 


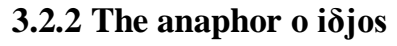

Particularly worrisome appears to be the case of the anaphoric expression $o$ idjos ${ }^{4} . \mathrm{O}$ $i \delta j o s$ does not fit into the binding principles as defined in (13) since it appears to be free in its local domain but bound within the sentence, combining therefore properties of both anaphors and pronominals. In addition, it systematically overlaps in reference with personal pronouns. In the current literature there are two major studies which attempt to address the problem, namely, Iatridou (1986) and Varlokosta \& Hornstein (1993) (henceforth $\mathrm{V} \& \mathrm{H}$ ).

Iatridou (1986) notes that there is not a principle to cover the option bound in the whole sentence but free in the governing category and hence she puts forward a new binding principle, namely Principle D, as a complement principle of Principle C.

24) Principle D

O idjos should be bound in the whole sentence but free in the governing category.

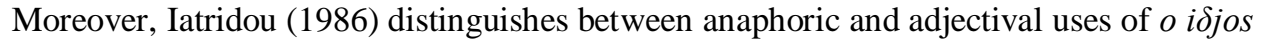
in order to account for cases where Principle D appears to be violated.

Coming next to Varlokosta \& Hornstein (1993), they note that $o$ idjos is or behaves like a pronominal since it has to be free in its local domain. Nevertheless, $o$ i $\delta j o s$, unlike the other pronouns in Modern Greek, has to be bound within its own sentence. This leads V\&H to conclude (as Iatridou 1986 does) that $o$ idjos does not fit neatly into the standard binding principles. More specifically, they suggest that when in object position $o$ idjos is an A'-bound pronoun (see also Enç 1989 for a similar approach). Their analysis is based on Koopman \& Sportiche's (1989) work of on logophoric pronouns. By generalizing Koopman \& Sportiche's analysis, V\&H propose that in the [Spec, CP] there is a null

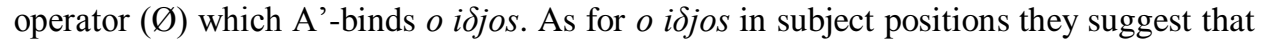
syntactically "it has none of the properties of object $o$ idjos since it functions like a standard pronominal expression and it has a focused reading" (V\&H 1993: 188). Therefore, they propose that the "pronoun found in subject position is $I \triangle J O S$ rather than

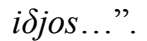

However, these two approaches are not without problems. To begin with Iatridou

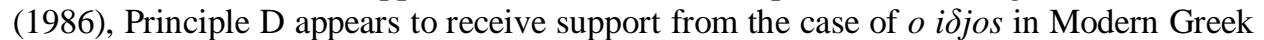
and from a class of long-distance reflexives, which do not take a local, like in Marathi and Dravidian languages. Yet, it cannot be maintained as a cross-language principle. This is due to the fact that in most of the cases, long-distance anaphors like $o$ i jjos allow local binding as well (like Chinese zijii, see Huang (1994, 2000). What is more, even the prediction that $o$ idjos should be bound in its sentence is falsified by examples like the following:

\footnotetext{
${ }^{4}$ Zribi-Hertz (1995) and Kiparsky (2002) also discuss, rather briefly though, o i $\delta j o s$ in their works. There are also two studies within the framework of Lexical Functional Grammar (LFG) by Kordoni (1995) and Lapata (1998), which will be not considered here.
} 
O Janis ipe oti pire me ti Maria

the John said that went-3sin with the Mary-acc

exӨes sto aerooromio. Otan eftasan ston elenxo

yesterday at the airport. When arrived-3pl to the control

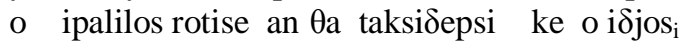

the officer asked if will travel-3sin and the same

'John said that he went to the airport with Mary yesterday. When

they reached the control the employee at the desk asked if he himself

is going to travel.'

In V\&H (1993), the basic distributional and configurational facts of $o$ i $\delta j o s$ follow from the properties of bound pronouns. The major advantage of this approach is that it describes more accurately the pronominal features of $o$ idjos. On the one hand, this approach partly explains the distributional overlap between $o$ i $\delta j o s$ and the clitic pronoun ton, which supports further the pronominal aspect of the former. On the other hand, their difference in dependency is given by the Ø-operator binding of $o$ idjos. However, it is not always unacceptable to find $o$ i ijos bound where the presence of an Ø-operator is not possible. Embedded questions like the one in (26) can falsify the prediction proposed in this analysis. Consider the following example which is judged acceptable by native speakers.

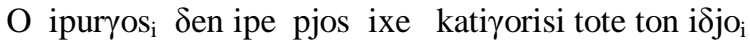

the minister not told who had accused then the same self

'The minister didn't tell who had accused him then.'

In this case, $o$ idjos seems to be bound directly by its antecedent without the need of an Ø-operator. According to V\&H (1993) sentence (26) is ungrammatical as the SpecCP position is occupied by the $w h$-word pjos and consequently there is no position for the Ø-operator.

\subsubsection{Discussion}

From the discussion so far it follows that syntactic factors play a central role in Modern Greek NP-anaphora. Nevertheless, a closer examination also reveals a number of cases which reinforce the view that the interpretation of Modern Greek NP-anaphora has been 'over-grammaticized', to borrow Levinson's (1987) phrasing. In other words, there are several cases that cannot be adequately described and explained within a purely syntactic account. In a nutshell, classical binding theory cannot account for the long-distance uses of the reflexive o eaftos $m u$ and it cannot provide an explanation for the differences in interpretation between an overt and a zero pronoun. Furthermore, there have been attempts to come up with better formulations for $o$ i $\delta j o s$, nevertheless, purely syntactic accounts remain problematic when it comes to the interpretation as well as to the systematic overlap in reference of $o$ idjos with personal pronouns. 


\section{The neo-Gricean pragmatic theory}

As shown, there is enough evidence against a purely syntactic account of NP-anaphora in Modern Greek (as well as across languages for that matter). Many considerations have been put forward, even within syntactic literature, suggesting that anaphora is a multidimensional phenomenon, integrating semantic, pragmatic (see Reinhart 1983 ${ }^{5}$ ) and discourse aspects (see Fox 1987, Frey 2005). Earlier attempts to provide a partially pragmatic account of anaphora phenomena has also been pursued in the works of Dowty (1980), Mittwoch (1983), Kempson (1984, 1988a, 1988b, 1988c), Kuno (1987) and Grodzinsky \& Reinhart (1993).

\subsection{Neo-Gricean pragmatic principles of communication}

The Gricean construal of meaning and communication is founded upon two basic

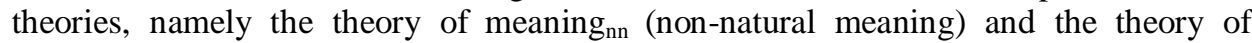
conversational implicatures (see Grice 1975, 1989). In both theories, Grice attempts to show the importance of non-conventional means in communication but also he draws the line between what is said and what is actually communicated in a communicative event.

\subsubsection{Levinson's inferential principles}

A recent development of the original Gricean theory on communication is the neoGricean pragmatic theory introduced and developed by Levinson (1987, 1991, 1998, 2000). Levinson suggests that the classical Gricean maxims of conversation be reduced to three pragmatic principles, namely, the Q- (Quantity), I- (Informativeness), and M(Manner) principles which are defined as follows:

27) The Q-Principle

Speaker's Maxim:

Do not provide a statement that is informationally weaker than your knowledge of the world allows, unless providing a stronger statement would contravene the I-principle.

Recipient's corollary:

Take it that the speaker made the strongest statement consistent with what he knows, and therefore that:

a) If the speaker asserted $\mathrm{A}(\mathrm{W})$, and $\langle\mathrm{S}, \mathrm{W}\rangle$ form a Horn scale (such that $\mathrm{A}(\mathrm{S})$ $\mathrm{A}(\mathrm{W}))$, then one can infer $\mathrm{K} \sim(\mathrm{A}(\mathrm{S}))$, i.e. that the speaker knows that the strongest statement will be false;

5 Reinhart (1983) argues for the distinction between co-reference, which is semantically/pragmatically determined and bound anaphora which is grammatically conditioned and constrained by c-command. For cases that don't fall under the bound variable constructions, Reinhart (1983: 167) puts forward the following maxim of Manner: "Be as explicit as conditions permit" i.e. by avoiding a bound variable interpretation the speaker intends non-coreference between the relevant expressions. 
b) If the speaker asserted $\mathrm{A}(\mathrm{W})$ and $\mathrm{A}(\mathrm{W})$ fails to entail an embedded sentence $\mathrm{Q}$, which a stronger statement $A(S)$ would entail, and $\{S, W\}$ form a contrast set, then one can infer $\sim K(Q)$, i.e. the speaker does not know whether $Q$ obtains or not.

The basic idea of the Q-principle is that the use of an expression (especially a semantically weaker one) in a set of contrastive semantic alternates (such as a Hornscale) Q-implicates the negation of the interpretation associated with the use of another expression (especially a semantically stronger one) in the same set. Seen the other way round, from the absence of an informationally stronger expression, we infer that the interpretation associated with the use of that expression does not hold. Hence, the Qprinciple is essentially negative in nature. The operation of the Q-principle is illustrated in (28).

28) Some of John's students are hard-working. $+>$ Not all of John's students are hard-working

29) The I-Principle

Speaker's Maxim: The Maxim of Minimization.

'Say as little as necessary', i.e. produce the minimal linguistic information sufficient to achieve your communicational ends (bearing the Q-principle in mind).

Recipient's corollary: The enrichment rule.

Amplify the informational content of the speaker's utterance, by finding the most specific interpretation, up to what you judge to be the speaker's m-intended point.

Specifically:

a) Assume that stereotypical relations obtain between referents or events, unless (i) this is inconsistent with what is taken for granted; (ii) the speaker has broken the Maxim of Minimization by choosing a prolix expression.

b) Assume the existence of actuality of what a sentence is 'about' if that is consistent with what is taken for granted.

c) Avoid interpretations that multiply entities referred to (assume referential parsimony); specifically, prefer co-referential readings of reduced NP's (pronouns or zero).

Mirroring the effects of the Q-principle, the central tenet of the I-principle is that the use of a semantically general expression I-implicates a semantically specific interpretation. More accurately, the implicature engendered by the I-principle is one that accords best with the most stereotypical and explanatory expectation given our knowledge about the world. By way of illustration, take (30).

30) Paul was waiting for the nurse to give him his medicine $+>$ Paul was waiting for the female nurse to give him his medicine

In this case an I-implicature is triggered by the stereotypically held expectation that a nurse is most of the times a female. 
31) M-Principle

Speaker's Maxim:

Don't use a prolix, obscure or marked expression without reason.

Recipient's Corollary:

If the speaker used a prolix or marked expression $\mathrm{M}$, he or she did not mean the same as he or she would have had he or she used the unmarked expression U-specifically he or she was trying to avoid the stereotypical associations and I-implicatures of U.

Unlike the Q- and I-principles, which operate primarily in terms of semantic informativeness, the metalinguistic M-principle ${ }^{6}$ is operative primarily in terms of a set of alternates that contrast in form. The fundamental axiom upon which this principle rests is that the use of a marked or prolix ${ }^{7}$ expression M-implicates the negation of the interpretation associated with the use of an alternative, unmarked expression in the same set.

32) The new manager is friendly.

$\mathrm{I}+>$ The new manager is friendly in the stereotypical sense

The new manager is not unfriendly

$\mathrm{M}+>$ The new manager is less friendly than the previous utterance suggests

Given the above tripartite classification of neo-Gricean pragmatic principles, the question that arises next is how inconsistencies arising from these potentially conflicting implicatures can be resolved. According to Levinson (2000), they can be resolved by an ordered set of precedence.

33) Levinson's resolution schema for the interaction

of the Q-, I-, and M-principles

a) Level of genus: $\mathrm{Q}>\mathrm{M}>\mathrm{I}$

b) Level of species: e.g. Q-clausal $>Q_{\text {-scalar }}$

Genuine Q-implicatures (where Q-clausal cancels rival Q-scalar) precede inconsistent Iimplicatures, but otherwise I-implicatures take precedence until the use of a marked linguistic expression triggers a complementary M-implicature to the negation of the applicability of the pertinent I-implicature (see e.g. Huang 2007 for further discussion).

\footnotetext{
${ }^{6}$ The Levinsonian Manner principle is directly related to the Gricean maxim of Manner and more precisely to the submaxims 'avoid obscurity of expression' and 'avoid prolixity' (see Grice 1989).

${ }^{7}$ The notion of markedness employed for the M-principle is in the spirit of Horn (1989) and Levinson $(1987,2000)$. In terms of formal characteristics, marked forms, in comparison to corresponding unmarked forms, are more morphologically complex and less lexicalized, more prolix and periphrastic, less frequent or usual, and less neutral in register. (Levinson 2000: 137). For a discussion on the different senses of 'markedness' and the possibility of doing away with it see Haspelmath (2006).
} 


\subsubsection{A revised neo-Gricean pragmatic apparatus}

Based on the theoretical framework above, Levinson $(1987,1991)$ puts forward the hypothesis that the three Binding Conditions of generative grammar can be reduced to a single grammatical condition with the effects of the other two being secured by default pragmatic inferences following from the systematic interaction of the I-, Q- and Mpragmatic principles. This idea is further pursued in Huang $(2000,2007)$ and a revised neo-Gricean pragmatic apparatus for the interpretation of anaphora is fleshed out.

A revised neo-Gricean pragmatic apparatus for anaphora:

a) Interpretation principles

i) The use of an anaphoric expression $x$ will I-implicate a co-referential interpretation unless (ii) or (iii).

ii) There is an anaphoric Q-scale $\langle x, y\rangle$, in which case, the use of $y$ will Qimplicate the complement of the I-implicature associated with the use of $x$ in terms of either reference.

iii) There is an anaphoric M-scale $\{x, y\}$, in which case, the use of $y$ Mimplicates the complement of the I-implicature associated with the use of $x$, in terms of either reference or expectedness i.e. (contrastiveness/emphaticness or logophoricity).

b) Consistency constraints

Any interpretation implicated by (i) above is subject to the requirement of consistency with:

i) Information saliency, so that

a) implicatures due to matrix constructions may take precedence over implicatures due to subordinate constructions, and

b) implicatures to co-reference may be preferred according to the saliency of antecedent in line with the hierarchy: topic> subject> object, etc.; and

ii) General implicature constraints, namely,

c) background assumptions,

d) contextual factors

e) meaning-nn, and

f) semantic entailments.

35) Referential content hierarchy

Anaphors $<$ pronominals $<$ r-expressions

Given (35), a choice to the left tends to reinforce co-referential readings, while a choice to the right tends to reinforce disjoint reference.

\section{A partial neo-Gricean pragmatic analysis for Modern Greek}

In the remaining of this paper I shall present a partial neo-Gricean pragmatic analysis of NP-anaphora in Modern Greek, seeking evidence for Levinson's and Huang's revised 
neo-Gricean pragmatic theory of anaphora as presented in the previous section ${ }^{8}$. More precisely, I shall argue for a partial pragmatic reduction of the interpretation of Modern Greek NP-anaphora based on the systematic interaction of the Q- I- and M-neo-Gricean pragmatic principles. The proposed pragmatic model is not a wholesale replacement of syntactic accounts. By contrast, it presupposes the existence of distinct syntactic, semantic and pragmatic levels of explanation. For this matter, the account proposed points in the direction of a division of labour between syntax and pragmatics.

\subsection{The reflexive $o$ eaftos $m u$}

As we have seen so far, the reflexive o eaftos mu may be used as: a) a locally bound reflexive or b) a long-distance anaphor. Let us examine these two cases separately.

In typical reflexive constructions like the one in (36) below, o eaftos $m u$ is bound by a local antecedent and it behaves as its English equivalent, namely, himself.

36) I Maria $\theta_{i}$ Oavmazi ton eafto tis $\mathrm{s}_{\mathrm{i}}$ the Mary admires the self hers 'Mary admires herself.'

In these distributions, reflexive o eaftos mu behaves like a typical [+anaphor, pronominal] NP in the sense of Chomsky $(1982,1986)$. Its interpretation is syntactically and semantically conditioned and it does not depend on contextual factors. For that matter we accept that local co-referential relationships are grammatically conditioned in Modern Greek and are interpreted by the syntactically defined binding principle A.

Given the formulation above, wherever a pronoun (semantically weak) is used instead of the reflexive o eaftos mu (semantically strong) the interpretation of the pronoun would be pragmatically inferred as follows:

I Maria $_{\mathrm{i}} \operatorname{tin}_{\mathrm{z}}$ $\theta$ avmazi

the Mary her admires

'Mary admires her.'

The reflexive o eaftos $m u$ and the pronoun will form a Q-scale <o eaftos $m u$, tin>. In (36) reflexivity is overtly marked in the syntax by the use of the reflexive o eaftos $m u$, hence according to binding condition $\mathrm{A}$, the use of the reflexive will give rise to a local co-referential interpretation. When the speaker alters to a clitic pronoun, as in (37), she/he invites the hearer to infer that she/he intends to avoid the local co-referential interpretation. Given that o eaftos $m u$ is semantically stronger than the pronoun, the choice of the semantically weaker clitic pronoun will Q-implicate the complement of the

\footnotetext{
${ }^{8}$ See also Valiouli (1994) for a more discourse oriented pragmatic analysis of the phenomenon of anaphora, Miltsakaki (2002) and Karamanis \& Miltsakaki (2006) for an anaphora model that combines the mechanisms of topic continuity and focusing. For a pragmatic approach to Spanish NP-anaphora see Blackwell (1994, 2000, 2001, 2003).
} 
interpretation associated with the use of the reflexive, i.e. disjoint reference. Therefore, binding principle B effect is pragmatically reduced by the operation of the Q-principle.

So far so good then for cases where reflexives and pronouns contrast in reference. What happens though in cases where this apparent complementarity breaks down like in (21) or (38)?

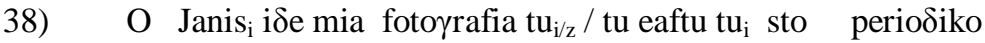
the John saw a picture him/the self his in the magazine 'John saw a picture of him/himself in the magazine.'

These distributions embarrass a purely syntactic account that predicts strict complementarity of pronouns and anaphors. Nevertheless, a pragmatic analysis is not defeated in such a way since it appears that the use of a reflexive in such environments is clearly pragmatic and it is different from its local reflexive use. More precisely, it has been proposed (see Runner, Sussman \& Tanenhaus 2003) that reflexives in 'picture NPs', appear to behave as logophors (we will return to logophoricity in a while). Furthermore, Levinson (2000: 327) notes that "pragmatic contrasts can be on various dimensions, and where an anaphor encodes perspectival information as well as referential dependency, the contrast with a pronoun can as well be in terms of the logophoric dimension".

As a result, when the reflexive o eaftos $m u$ is used in these long-distance environments, the use of a pronoun still generates a contrast yet because the reflexive is marked for other kinds of pragmatic meaning as well (e.g. logophoricity), the contrast is at a this very level of logophoricity. Therefore the account can be spelled out as follows: The use of the unmarked pronoun indicates that the speaker wants to go for a coreferential reading. Reversion to the more marked reflexive o eaftos $m u$, will generate an M-implicature in terms of logophoricity.

\subsection{Overt and zero pronouns}

Modern Greek is a typical pro-drop language and as a result, it normally drops the overt subject $^{9}$ of clauses (pro-drop parameter) ${ }^{10}$. Nevertheless, since pro-dropping is only a general tendency, it means that an overt phrase can equally occupy the relevant slot in the clause. Let us concentrate here in cases where the full pronoun aftos is used instead of a zero pronoun.

On this basis there is a rather clear question to be addressed to, namely, what is the reason for using the pronoun aftos where a non-morphologically expressed pronoun can be used. In other words, what motivates speakers to use a marked construction (aftos) over an unmarked one (zero)? There are good reasons to believe that the preference of the pronoun aftos over the zero pronoun is inherently pragmatic. In other words, it will be claimed that speakers generally tend to avoid using the full pronoun aftos or the anaphor $o$ idjos without any particular purpose. By contrast, when they opt for one of

\footnotetext{
9 Modern Greek drops only subjects but not objects.

${ }^{10}$ The zero subject of finite clauses is known under the term pro, hence the pro-drop parameter.
} 
these two marked anaphoric expressions they intend to convey readings which cannot be inferred by the use of a zero pronoun.

The distribution zero/aftos is a twofold case. On the one hand, there are contexts in which the use of the more marked aftos, where the zero could have occurred, results in the disjoint interpretation of the overt pronoun like in (39).

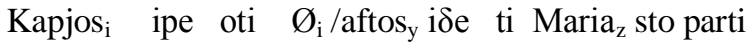
somebody said that (he)/he saw the Mary at the party 'Somebody said that he saw Mary at the party.'

On the other hand, there are cases where there is an overlap in reference between the zero pronoun and aftos.

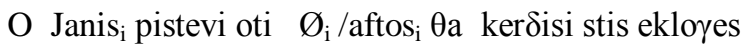

the John believs that (he)/he will win at the elections

'John believes that he will win at the elections.'

As mentioned before, these cases are not problematic at all for the neo-Gricean pragmatic apparatus since the M-principle operate at various distinct levels of pragmatic meaning. As a result, examples like (39) and (40) are interpreted in the following way: When a zero pronoun is used co-reference is given by the I-principle. In the case of (39), reversion to a more marked full pronoun, will $\mathrm{M}$-implicate a contrast in reference. By contrast, in (40) the use of aftos expresses a more emphatic/contrastive meaning. Therefore, in contexts like these, the use of the more marked full pronoun M-implicates emphaticness/contrastiveness in the following way. Given the set of alternates $\{\varnothing$, aftos\}, the choice of the more prolix pronoun instead of the zero will M-implicate the intention of the speaker to go for a more marked interpretation in terms of emphasis and contrast.

The observation that there is a general tendency to avoid marked forms, unless there is a reason to do so, is not novel in the literature. Chomsky $(1981,1982)$ has proposed the so called 'avoid pronoun principle' according to which, a null pronoun is preferred where co-reference is intended. In a different case, the use of an overt pronoun would be interpreted as disjoint in reference. This principle indeed describes and explains the rationale behind the preference of a zero where the option between a null versus a full pronoun in pro-drop languages like Modern Greek is open. Yet, this principle has a clear pragmatic content and it can follow directly from the interaction of the neo-Gricean pragmatic principles as described above.

\subsection{On the interpretation of $o$ i $\delta j o s$}

As already mentioned, $o$ idjos overlaps systematically in reference with personal pronouns. At the risk of redundancy, consider the following example: 


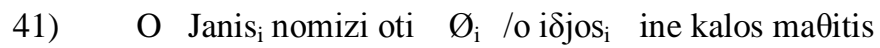
the John thinks that (he) the same is good student 'John thinks that he is a good student.'

In these contexts, there is some sort of unexpectedness (Edmondson \& Plank 1978, Huang 2000, Levinson 2000) in the sense that the preferred interpretational pattern is not affected by the use of $o$ i $\delta j o s$ instead of the pronominal form. As Huang (2000: 225) notes, "this unexpectedness may turn out to be logophoricity, emphaticness/contrastiveness or something yet to be discovered".

\subsubsection{Emphaticness/contrastiveness}

Modern Greek does not codify emphasis and contrast with purpose-specific pronouns.

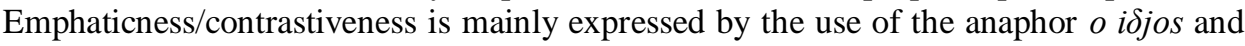
full pronouns. It is fairly clear from examples like (41) that $o$ idjos marks contrastive/emphatic content which is also accompanied by a natural negative gloss of the sort 'and not anyone else'.

This sensitivity of $o$ i $\delta j o s$ in emphatic/contrastive interpretations may also be related to the semantics of the idjos (same) part of the anaphoric expression. It could be argued that the use of $o$ idjos generates identity statements (see Alrenga 2006, 2007) and that its anaphoric occurances are rather conventionalised as such. This suggestion further supports the view that the interpretation of $o$ idjos is semantically and pragmatically motivated. What is more, in this way we can by-pass the problem raised in Iatridou (1988), where the syntactic Principle D could only account for the anaphoric uses of $o$ idjos.

\subsubsection{Logophoricity}

Logophoricity and the use of logophoric pronouns were initially observed in a number of African languages such as Ewe, Dogon, Tuburi, Aghem and so on (see Huang 2000 for a variety of examples). In these languages, there is a separate paradigm of logophoric pronouns, i.e. a class of pronouns dedicated to the encoding of logophoric interpretations. Nevertheless, apart from the purpose-specific logophoric pronouns, reflexives can be used logophorically under certain conditions (see Culy 1994, 1997, Huang 1991, 1994, 2000, Sells 1987, Zribi-Hertz 1989).

According to Culy (1997: 845), "logophoric pronouns are usually described as pronouns that are used to refer to the person whose speech, thoughts, or feelings are reported or reflected in a given linguistic context". This 'person' is also referred to as the 'internal protagonist' (Huang 2000) or the 'minimal subject of consciousness' (ZribiHertz 1989). In particular, Zribi-Hertz (1989) identifies the subject of consciousness with Kuno's (1987) sense of logophoricity as "a semantic property assigned to a referent whose thoughts or feelings, optionally expressed in speech, are conveyed by a portion of the discourse" (Zribi-Hertz 1989: 711). Logophoricity is also related with the notion of 'point of view', yet Culy (1997) claims that logophoricity proper is rather distinct form 
point of view. More precisely, Culy points out that "morphologically distinct logophoric pronouns are grammatically licensed in indirect discourse....and only secondarily indicate point of view" (Culy 1997: 846). In a similar fashion, 'indirect reflexives' (reflexives which can be used logophorically) "can express point of view if they do not have grammatically determined antecedents" (Culy 1997: 856).

As Kuno (1987) and Kuno \& Kaburaki (1977) note, the contrast between a pronoun and an anaphor, where there is a free choice, is semantic/pragmatic in nature and it is associated with the notion of 'point of view'. This seems to be the case with Modern Greek $o$ i jjos when it occurs in embedded subject positions instead of a zero pronoun (see again example 41). A way forward is to suggest that $o$ idjos, apart from emphasis and contrast, also encodes logophoricity in the sense of Kuno (1987) and Kuno \& Kaburaki (1977). The logophoric interpretation of the sentence can be analyzed as follows: When the null pronoun is used, the belief that John is a good student is expressed by the speaker. In other words, the speaker states his own view about the protagonist of the sentence who is John. By contrast, when o idjos is used, the sentence conveys a more logophoric interpretation in the sense that the internal protagonist's point of view is also expressed. As we understand it, the use of the anaphor $o$ idjos is logophoric.

The logophoric interpretation of $o$ ijjos can be accounted for by the systematic interaction of the neo-Gricean pragmatic principles. When there is an option between a

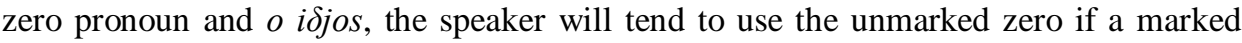
message is not intended. By contrast, if a logophoric interpretation is intended, the more

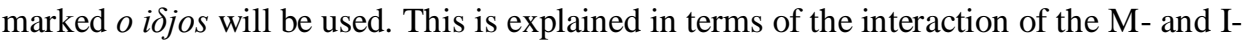

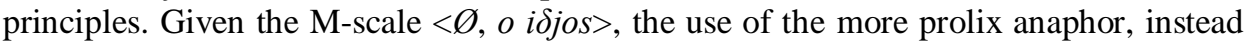
of the unmarked zero, will M-implicate the intention of the speaker to go for a logophoric interpretation.

\subsection{Parameters constraining anaphora}

As it is already mentioned, various syntactic, pragmatic, semantic and cognitive parameters appear to interact systematically in the case of anaphora resolution. It has been shown (Huang 1991, 1994, 2000, Blackwell 1994, 2000, 2001, 2003) that the predictions made by the neo-Gricean pragmatic principles are constrained inconsistent with certain factors such as world knowledge, semantic entailments or information saliency/aboutness.

Interpretations that follow from the systematic interaction of the neo-Gricean pragmatic principles do not survive when inconsistent with our knowledge of the world. By way of illustration, consider the examples.

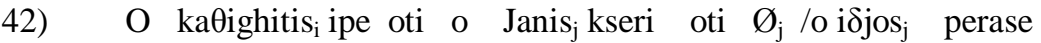
the professor said that the John knows that (he)/the same passed to diayonisma

the exam

'The professor said that John knows that he passed the exam. 
The M-implicature which should have been generated by the use of the more prolix anaphoric expression $o$ idjos is ruled out since our knowledge about the world is that students participate in and pass/fail exams. World knowledge in these cases equals to certain stereotypical relations about the world.

In a study on Spanish NP anaphora Blackwell $(1994,2000)$ also observes that semantic entailments can override inconsistent M-implicatures of non-co-reference. In her example (Blackwell 2001: 929) the use of a more prolix NP, where a zero could have occurred, does not trigger an M-inference of non-co-reference. This is also borne out in Modern Greek.

43) I Maria $a_{i}$ niazete mono ji' aftin ${ }_{i}$ ke panda kani to Siko tis the Mary cares only about her and always does the own hers 'Mary cares only about her and always she does whatever she wants.'

44) I Maria $a_{\mathrm{i}}$ niazete mono ja ti Maria $\mathrm{i}_{\mathrm{i}}$ ke panda kani to Siko tis the Mary cares only about the Mary and always does the own hers

'Mary cares only about Mary and always she does whatever she wants.'

As the M-principle predicts, the use of the more prolix NP ti Maria where the less prolix pronoun could have used, should M-implicate a non-co-referential interpretation. However, there is a preference for the co-referential reading of the r-expression which can be attributed to semantic entailment. In that case, as Blackwell explains, the Mimplicature is cancelled since the NP ti Maria "is interpreted as a reiterated NP", that is, semantically entailed by the subject NP (Blackwell 2001: 930).

The theory of antecedent saliency can be proved to be an important factor in Modern Greek anaphoric patterns. One can claim that the interpretation of the null pronouns is also regulated by 'aboutness' factors since it is usually the case that a null pronoun is coreferential with the most prominent entity in the sentence. Consider the example.

O Janis ${ }_{\mathrm{i}}$ xorise me ti Maria . Kanis Sen kseri $\varnothing_{\mathrm{i}}$ the John split with the Mary. Nobody not knows (he)

ti kani meta apo afto

what does after this

'John split with Mary. Nobody knows how he is coping after that.'

In (45) the null pronoun can potentially be co-referential with either of NPs in the first sentence. However, the most preferred reading is the one shown in the example above. In that case John is the topic in discourse, hence more salient than Mary; as a result the hearer I-infers that the speaker gives him/her information about the topic of the discourse which is John. Note here that any change in the topic would be marked by the use of the more prolix full pronoun as (46) illustrates. 
46) O Janis ${ }_{\mathrm{i}}$ xorise me ti Maria $\mathrm{j}_{\mathrm{j}}$ Kanis Sen kseri afti $\mathrm{i}_{\mathrm{j}}$ the John split with the Mary. Nobody not knows she

ti kani meta apo afto

what does after this

'John split with Mary. Nobody knows how she is coping after that.'

\section{Conclusion}

In this paper, I addressed the issue of interpreting anaphoric NPs in Modern Greek and I proposed an alternative analysis based on the systematic interaction of the neo-Gricean pragmatic principles of communication, which provides a neat and more elegant approach to NP-anaphora resolution. Summarising our main findings, it was claimed that the interpretation of the anaphor o eaftos mu remains grammatically specified and it is subject to binding condition A. Yet, in those contexts in which o eaftos $m u$ can receive a long distance antecedent a co-referential reading is given by the I-principle. Moreover, the use of $o$ idhios instead of a null pronoun will give a preferred contrastive/emphatic and/or logophoric interpretation given the M-principle. Also, in the distributions zero vs. overt pronoun, preferred interpretations are given by the M-principle. In these cases Minferences can give either a disjoint or a contrastive/emphatic reading depending on the context. Finally it was shown that interpretations that follow from the systematic interaction of the neo-Gricean pragmatic principles do not survive when inconsistent with our knowledge of the world.

The findings of this study provide evidence for an account of NP-anaphora in terms of the division of labour between syntax and pragmatics and more accurately in terms of the systematic interaction of the neo-Gricean pragmatic principles. Despite the fact that syntax and pragmatics operate on distinct levels of linguistic explanation they appear to interact systematically in the case of anaphora resolution. On the one hand, syntax sets certain restrictions on distributions and regulates the part of interpretations, which are related to grammatical structure. On the other hand, the choice of anaphoric expressions by the speakers and their interpretation by addressees is heavily dependent on preference, which is regulated by principles of language use and communication.

\section{References}

Anagnostopoulou, Elena and Everaert, Martin. 1999. "Towards a more complete typology of anaphoric expressions." Linguistic Inquiry 30: 97-119.

Arlenga, Peter. 2006. "Scalar (non-) identity and similarity." In Proceedings of the $25^{\text {th }}$ West Coast Conference on Formal Linguistics (WCCFL 25).

Arlenga, Peter. 2007. "Types, tokens and identity." In Proceedings of the $38^{\text {th }}$ Meeting of the North East Linguistic Society (NELS 38).

Edmondson, Jerold and Plank, Frank. 1978. "Great expectations: An intensive self analysis." Linguistics and Philosophy 2: 373-413.

Blackwell, Sarah E. 1994. A neo-Gricean approach to Spanish NP-anaphora. Ph.D. dissertation: University of Pittsburgh. 
Blackwell, Sarah E. 2000. "Anaphora interpretations in Spanish utterances and the neoGricean pragmatic theory." Journal of Pragmatics 32: 389-424.

Blackwell, Sarah E. 2001. "Testing the neo-Gricean pragmatic theory of anaphora: The influence of consistency constraints on interpretations of coreference in Spanish." Journal of Pragmatics 33: 901-941.

Blackwell, Sarah E. 2003. Implicatures in discourse: The case of Spanish NP-anaphora. Amsterdam: John Benjamins Publishing Company.

Chiou, Michael. 2010. NP-anaphora in Modern Greek: A neo-Gricean pragmatic approach. Newcastle-upon-Tyne: Cambridge Scholars Publishing

Chomsky, Noam. 1981. Lectures on Government and Binding. Dordrecht: Foris.

Chomsky, Noam. 1982. Some Concepts and Consequences of the Theory of Government and Binding. Cambridge, Mass.: The MIT Press.

Chomsky, Noam. 1986. Knowledge of Language, its Nature, Origin and Use. New York: Praeger.

Chomsky, Noam. 1995. The Minimalist Program. Cambridge, Mass.: The MIT Press.

Culy, Christopher. 1994. "Aspects of logophoric marking." Linguistics 32: 1055-1094.

Culy, Christopher. 1997. "Logophoric pronouns and point of view." Linguistics 35: 845859.

Dowty, David. 1980. "Comments on the paper by Bach and Partee." In Papers from the parasession on pronouns and anaphora, Kreiman, J. \& Ojeda, E. A. (eds), 29-40. Chicago: Chicago Linguistic Society.

Fox, Barbara. 1987. Discourse Structure and Anaphora. Cambridge: Cambridge University Press.

Frey, Werner. 2005. "Pragmatic properties of certain German and English left peripheral constructions." Linguistics 43 (1): 89-129.

Grice, Paul. 1975. "Logic and Conversation." In Syntax and Semantics 3: Speech Acts, Cole Peter and J. L. Morgan (eds), 41-58. New York: Academic Press.

Grice, Paul. 1982. "Meaning Revisited." In Mutual Knowledge, N. V. Smith (eds), 223243. New York: Academic Press.

Grice, Paul. 1989. Studies in the Way of Words: Cambridge, MA: Harvard University Press.

Grodzinsky, Yosef and Reinhart, Tanya. 1993. "The innateness of binding and coreference." Linguistic Inquiry 24: 69-101.

Haspelmath, Martin. 2006. "Against markedness (and what to replace it with)." Journal of Linguistics 42: 25-70.

Holton, David, Mackridge, Peter and Philippaki-Warburton, Irene, 1997. Greek: A Comprehensive Grammar of the Modern Language. London: Routledge.

Horn, Laurence. 1989. A Natural History of Negation. Chicago: The University of Chicago Press.

Huang, Yan. 1991. "A neo-Gricean Pragmatic Theory of Anaphora.” Journal of Linguistics 27: 301-333.

Huang, Yan. 1994. The Syntax and Pragmatics of Anaphora: A Study with special reference to Chinese. Cambridge: Cambridge University Press.

Huang, Yan. 2000. Anaphora: A Cross Linguistic Study. Oxford: Oxford University Press. 
Huang, Yan, 2004. "Anaphora and the pragmatics - syntax interface." In Handbook of pragmatics, Laurence R. Horn and George Ward (eds), 288-314. Oxford: Blackwell.

Huang, Yan. 2007. Pragmatics. Oxford: Oxford University Press.

Iatridou, Sabine. 1986. "An anaphor not bound in its category." Linguistic Inquiry 17: 766-772.

Iatridou, Sabine. 1988. "Clitics, anaphors and the problem of co-indexation." Linguistic Inquiry 19: 698-703.

Iatridou, Sabine, 1993. "On nominative case assignment and a few related things." MIT Working Papers in Linguistics 19: Papers on Case and Agreement II. 175-195.

Joseph, Brian D. and Philippaki-Warburton, Irene. 1987. Modern Greek. London: Croom Helm.

Karamanis, Nikiforos and Miltsakaki, Eleni. 2006. "Centering theory on Greek Narratives and Newspaper Articles." In The World of Texts: A Collection of Articles in Honor of G. Babiniotis.

Karanasios, Giorgos. 1989. "Kenes katigories ke sintaktiko ipokimeno sta Elinika (Empty categories and syntactic subject in Greek)." In Studies in Greek Linguistics. Proceedings of the $10^{\text {th }}$ annual meeting of the Department of Linguistics: 169-185. University of Thessaloniki.

Kempson, Ruth. 1984. "Pragmatics, anaphora and logical form". In Meaning, form and use in context: linguistic applications, Schiffrin, D. (ed), 1-10. Washington DC: Georgetown University Press.

Kempson, Ruth. 1988a. "Grammar and conversational principle." In Linguistics: the Cambridge survey, Newmeyer, F.J. (ed), Vol 2, 139-163. Cambridge: Cambridge University Press.

Kempson, Ruth. 1988b. "Logical form: the grammar cognition interface." Journal of Linguistics 24: 393-431.

Kempson, Ruth. (ed.). 1988c. Mental representations: the interface between language and reality. Cambridge: Cambridge University Press.

Kiparsky, Paul. 2002. "Disjoint reference and the typology of pronouns." In More than Words, Ingrid, K. and Stiebels, B. (eds), Studia Grammatica 53: 179-226. Berlin: Akademie Verlag.

Koopman, Hilda and Sportiche, Dominique. 1989. "Pronouns, logical variables and logophoricity in Abe." Linguistic Inquiry 20: 555-588.

Kordoni, Valia. 1995. "Psychological predicates in Modern Greek." In Greek linguistics '95, Drachman, G., Malikouti-Drachman, A., Klidi, C. \& Fykias, J. (eds.), 535-544. Proceedings of the $2^{\text {nd }}$ international conference on Greek linguistics. Graz: W Neugebauer Verlag.

Kuno, Susumu. 1987. Functional Syntax: Anaphora, Discourse and Empathy. Chicago: University of Chicago Press.

Kuno, Susumu and Kaburaki, Etsuko. 1977. "Empathy and syntax." Linguistic Inquiry 8: 627-672.

Lapata, Maria. 1998. "Anaphoric Binding in Modern Greek". In Proceedings of the LFG98 Conference, CSLI Publications: The University of Queensland, Brisbane. [on-line] available from: /www.-csli.Stanford.edu/publications/. 
Levinson, Stephen C. 1987. "Pragmatics and the grammar of Anaphora: A partial pragmatic reduction of binding and control phenomena." Journal of Linguistics 23: 379-434.

Levinson, Stephen C. 1991. "Pragmatic Reduction of Pragmatic Conditions Revisited." Journal of Linguistics 27: 107-161.

Levinson, Stephen C. 2000. Presumptive Meanings: The Theory of Generalized Conversational Implicature. Cambridge: The MIT Press.

Mackridge, Peter. 1985. The Modern Greek Language: A Descriptive Analysis of Standard Modern Greek. Oxford: Oxford University Press.

Miltsakaki, Eleni. 2002. "Toward an aposynthesis of topic continuity and intrasententential anaphora. " Computational Linguistics 28 (3): 319-355.

Mittwoch, Anita. 1983." Backward anaphora and discourse structure." Journal of Pragmatics 7: 129-139.

Philippaki-Warburton, Irene. 1987. "The theory of empty categories and the pro-drop parameter in Modern Greek." Journal of Linguistics 23: 289-318.

Philippaki-Warburton, Irene and Catsimali, Georgia. 1999. "On Control in Greek." In Studies in Greek Syntax, Alexiadou, A. Horrocks, G. and Stavrou, M. (eds.), 153168.

Runner, Jeffrey T, Sussman, Rachel S and Tanenhaus, Michael K. 2003. "Assignment of reference to reflexives and pronouns in picture noun phrases: Evidence from eye movements." Cognition 89: B1-B13.

Reinhart, Tania. 1983. Anaphora and Semantic Interpretation. London: Croom Helm.

Reinhart, Tania. and Reunald, Eric. 1993. "Reflexivity." Linguistic Inquiry 24: 657-720.

Sells, Peter. 1987. “Aspects of logophoricity.” Linguistic Inquiry 18: 445-479.

Terzi, Arhonto. 1991. "PRO and Obviation in Modern Greek Subjunctives." In Proceedings of WCCFL 10: 471-482

Terzi, Arhonto. 1993. "PRO and Null Case in Finite Clauses." Unpublished manuscript, University of Ottawa.

Valiouli, Maria. 1994. “Anaphora, agreement and right dislocations in Greek.” Journal of Semantics 11: 55-82.

Varlokosta, Spyridoula. 1993. "Control in Modern Greek." University of Maryland Working Papers in Linguistics 1: 144-163.

Varlokosta, Spyridoula. 1994. Issues on Modern Greek sentential complementation. Ph.D. dissertation, University of Meryland, College Park.

Varlokosta, Spyridoula and Hornstein, Norbert. 1993. "A Bound Pronoun in Modern Greek." Natural Language and Linguistic Theory 11: 175-195.

Zribi-Hertz, Anne. 1989. "Anaphor binding and narrative point of view: English reflexive pronouns in sentence and discourse." Language 65: 695-727.

Zribi-Hertz, Anne. 1995. "Emphatic or Reflexive? On the Endophoric character of French lui-même and similar complex pronouns." Journal of Linguistics 31: 333374.

\section{About the author}

Michael Chiou holds a PhD from the University of Reading titled 'NP-anaphora in Modern Greek: A neo-Gricean pragmatic approach'. He has also received an MA in Linguistic 
Science (Reading) and a BA in English Language, Linguistics and Literature (Athens). His main research interests are in pragmatics, semantics and syntax focusing on the pragmatics and its interfaces. In his thesis, he proposes that NP-anaphora patterns in Modern Greek can be partially accounted for by the employment of a pragmatic apparatus formulated upon the Levinsonian neo-Gricean pragmatic principles. He has taught syntax and pragmatics in the University of Hertfordshire and he supervises for the Li2 'Meanings' Linguistics Tripos at the University of Cambridge. His work has been presented in conferences across Europe. 